ARTICLE

https://doi.org/10.1038/s41467-020-15850-4

OPEN

\title{
CO oxidation activity of non-reducible oxide-supported mass-selected few-atom Pt single-clusters
}

Atsushi Beniya (i] ${ }^{1 凶}$, Shougo Higashi(i] ${ }^{1 凶}$, Nobuko Ohba (1) ${ }^{1}$, Ryosuke Jinnouchi ${ }^{1}$, Hirohito Hirata ${ }^{2} \&$ Yoshihide Watanabe ${ }^{1}$

Platinum nanocatalysts play critical roles in CO oxidation, an important catalytic conversion process. As the catalyst size decreases, the influence of the support material on catalysis increases which can alter the chemical states of Pt atoms in contact with the support. Herein, we demonstrate that under-coordinated Pt atoms at the edges of the first cluster layer are rendered cationic by direct contact with the $\mathrm{Al}_{2} \mathrm{O}_{3}$ support, which affects the overall $\mathrm{CO}$ oxidation activity. The ratio of neutral to cationic Pt atoms in the Pt nanocluster is strongly correlated with the $\mathrm{CO}$ oxidation activity, but no correlation exists with the total surface area of surface-exposed Pt atoms. The low oxygen affinity of cationic Pt atoms explains this counterintuitive result. Using this relationship and our modified bond-additivity method, which only requires the catalyst-support bond energy as input, we successfully predict the $\mathrm{CO}$ oxidation activities of various sized Pt clusters on $\mathrm{TiO}_{2}$.

\footnotetext{
${ }^{1}$ Toyota Central R\&D Labs, Inc., 41-1 Yokomichi, Nagakute, Aichi 480-1192, Japan. ${ }^{2}$ Toyota Motor Corporation, 1200 Mishuku, Susono, Shizuoka 410-1193, Japan.凶email: beniya@mosk.tytlabs.co.jp; shigashi@mosk.tytlabs.co.jp
} 
recious metal nanoclusters, with diameters of a few nanometres or less, are of particular importance as catalysts in heterogeneous catalytic conversions such as the oxygen reduction reaction for fuel cells ${ }^{1,2}$, hydrogenation reactions in organic chemistry ${ }^{3,4}$, and CO oxidation (Eq. (1)), which are designed to control emissions from combustion sources ${ }^{5-7}$.

$$
\mathrm{CO}+1 / 2 \mathrm{O}_{2} \rightarrow \mathrm{CO}_{2}
$$

Reducing the catalyst size increases the number of atoms that are exposed on their surface (Supplementary Fig. 1) and therefore can increase the catalytic efficiency in terms of mass loading. However, when the diameter of the catalytic cluster is in the range of a few nanometres, the interactions between the cluster and the support material holding the cluster become significant ${ }^{8,9}$. For a nanocluster with a diameter of $\sim 1 \mathrm{~nm}$ that consists of $\sim 20$ atoms, roughly $70 \%$ of the atoms are in direct contact with the support material, and consequently, the effect of the support material on the catalytic reaction is not negligible ${ }^{5}$. To clarify this effect quantitatively, a combination of model systems, in which uniform mass-selected clusters are distributed on well-defined single crystal metal oxide support substrates, simple catalytic reactions such as $\mathrm{CO}$ oxidation, and surface-sensitive analytic techniques are required $6,7,10,11$.

Two types of surface reaction mechanism have been discussed for $\mathrm{CO}$ oxidation over platinum group metal (PGM) nanocatalysts: the Mars-van Krevelen mechanism, in which the reaction involves lattice oxygen in the support, and the Langmuir-Hinshelwood (L-H) mechanism, in which the reaction occurs on the catalyst surface without the involvement of oxygen in the support ${ }^{5,12-14}$. The type of reaction that occurs depends on the reducibility of the support material. $\mathrm{Al}_{2} \mathrm{O}_{3}$ is a non-reducible oxide and previous studies have confirmed that L-H-type $\mathrm{CO}$ oxidation occurs on $\mathrm{Pt}$ nanoparticle (NP) catalysts with diameters of approximately 1-20 nm supported on $\mathrm{Al}_{2} \mathrm{O}_{3}{ }^{13,14}$. Although infrared spectroscopy has confirmed the existence of oxidized Pt atoms in the NPs ${ }^{15}$, it is not clear whether the Pt atoms on the support are fully oxidized or partly oxidized or how the support affects the chemical states of $\mathrm{Pt}$ atoms in contact with the support and the resulting CO oxidation activity. An in-depth understanding of the oxidation state of Pt on such oxides and its relationship to the $\mathrm{CO}$ oxidation activity is needed.

Infrared reflection absorption spectroscopy (IRAS) is often used as a tool for identifying the chemical states of $\mathrm{Pt}$ nanoclusters $^{16-19}$. If oxidized $\mathrm{Pt}$ exists in a nanocluster, its identification should be possible using IRAS. Thus we prepare mass-selected $\mathrm{Pt}_{n}$ single-size clusters $(7 \leq n \leq 35, n=$ number of $\mathrm{Pt}$ atoms in a cluster) on the surface of a well-defined single crystalline oxide support $\left(\mathrm{Al}_{2} \mathrm{O}_{3}\right.$ or $\left.\mathrm{TiO}_{2}\right)$ and perform IRAS measurements. We also perform the temperature-programmed reaction (TPR) of $\mathrm{CO}_{2}$ to determine how many introduced $\mathrm{CO}$ and $\mathrm{O}$ molecules are converted to $\mathrm{CO}_{2}$ for various Pt cluster sizes, and thus obtain information about the size and chemical state dependence of the $\mathrm{CO}$ oxidation activity.

In this study, we find that the $\mathrm{CO}$ oxidation mass activities for clusters with a second Pt layer are higher than those for clusters with a single layer, despite their small number of surface-exposed $\mathrm{Pt}$ atoms or large number of embedded atoms. We also show that the highest $\mathrm{CO}$ oxidation activity (amount of $\mathrm{CO}_{2}$ produced per deposited $\mathrm{Pt}_{n}$ single clusters. Note that the total number of deposited $\mathrm{Pt}$ atoms is the same for each sample; $\leq 0.02 \mathrm{ML} ; 1 \mathrm{ML}=$ $1.5 \times 10^{15} \mathrm{Pt}$ atoms $\mathrm{cm}^{-2}$ ) is achieved when the ratio of neutral to cationic Pt atoms in the nanocluster is maximized. We detect no correlation between the number of surface-exposed $\mathrm{Pt}$ atoms (i.e. the surface area of the Pt cluster) and the amount of $\mathrm{CO}_{2}$ produced. These results are explained by an enhancement of the bond strengths between the Pt atoms located at the edges of the first cluster layer and the support oxide, which alters the chemical state of these Pt atoms from neutral to cationic, thus weakening the association of $\mathrm{O}$ with cationic $\mathrm{Pt}$ and resulting in low $\mathrm{CO}_{2}$ production. Furthermore, using the discovered relationship and our modified bond-additivity model (BAM), which uses only the bond energy between a single catalyst atom (in this study, $\mathrm{Pt}$ ) and the support $\left(\mathrm{Al}_{2} \mathrm{O}_{3}\right.$ or $\left.\mathrm{TiO}_{2}\right)$ to construct the thermodynamically stable morphologies of the clusters, we show that it is possible to predict the $\mathrm{CO}$ oxidation activities of the constructed cluster models.

\section{Results}

Model structures of $\mathrm{Pt}$ clusters on $\mathrm{Al}_{2} \mathrm{O}_{3}$ and $\mathrm{TiO}_{2}$ substrates. Two well-defined model catalyst systems were prepared by depositing a small amount of mass-selected Pt clusters uniformly on $\mathrm{Al}_{2} \mathrm{O}_{3} / \mathrm{NiAl}(110)$ and $\mathrm{TiO}_{2}(110)$ surfaces without cluster fragmentation and aggregation ${ }^{20,21} \cdot \mathrm{Al}_{2} \mathrm{O}_{3} / \mathrm{NiAl}(110)$ surfaces are used commonly in model catalyst studies because $\mathrm{Al}_{2} \mathrm{O}_{3}$ films grown epitaxially on $\mathrm{NiAl}(110)$ exhibit a high degree of crystallinity, low surface roughness, and excellent preparation reproducibility 22,23 . Although $\mathrm{Al}_{2} \mathrm{O}_{3}$ is an insulator, the $\mathrm{Al}_{2} \mathrm{O}_{3}$ film is sufficiently thin to avoid charge accumulation, which enables us to utilize experimental methods involving ions and electrons to characterize the model catalyst systems. The $\mathrm{Al}_{2} \mathrm{O}_{3}$ film contains unsaturated penta-coordinated $\mathrm{Al}^{3+}$ cations ${ }^{22}$, known as $\mathrm{Pt}$ anchor sites on the (100) facets of the $\gamma-\mathrm{Al}_{2} \mathrm{O}_{3}$ surface $^{24,25}$, which can suppress the thermal diffusion of $\mathrm{Pt}$ atoms on the $\mathrm{Al}_{2} \mathrm{O}_{3}$ film. For the $\mathrm{TiO}_{2}$ substrate, the $\mathrm{TiO}_{2}(110)$ surface was annealed at $\sim 950 \mathrm{~K}$ for $10 \mathrm{~min}$ to introduce oxygen vacancies and to ensure electrical conductivity ${ }^{26}$.

CO oxidation activity as a function of Pt cluster size. Figure 1a shows the procedure employed for studying the $\mathrm{CO}$ oxidation activity by the TPR of $\mathrm{CO}_{2}$ formed by the reaction of $\mathrm{CO}$ and $\mathrm{O}$ (Eq. (1)) on the model structure; first, Pt clusters were saturated by labelled $\mathrm{O}_{2}\left(1000 \mathrm{~L}\right.$ of ${ }^{18} \mathrm{O}_{2}$ at $300 \mathrm{~K}, 1 \mathrm{~L}=1 \times 10^{-6}$ Torr $\left.\cdot \mathrm{s}\right)$, followed by saturation adsorption of ${ }^{13} \mathrm{CO}$ at $88 \mathrm{~K}$, and finally the TPR measurement was performed ${ }^{27}$. We only detected $\mathrm{CO}_{2}$ with a mass of $m=47$ regardless of the cluster size (Supplementary Fig. 2), indicating that $\mathrm{CO}_{2}$ is produced from the introduced ${ }^{18} \mathrm{O}_{2}$ and ${ }^{13} \mathrm{CO}$ without the involvement of lattice oxygen in $\mathrm{Al}_{2} \mathrm{O}_{3}$, which is consistent with previous reports ${ }^{13,14}$.

Figure $1 \mathrm{~b}$ represents the amount of produced $\mathrm{CO}_{2}$ from sample surface with mass-selected $\mathrm{Pt}$ single clusters relative to the number of $\mathrm{Pt}$ atoms in the cluster, which was estimated from the area intensity analysis using the TPR spectra shown in Fig. 1c. As clearly seen in Fig. $1 \mathrm{~b}$, the amount of produced $\mathrm{CO}_{2}$ peaks at $n=$ 24. Figure 1d represents the total amount of unreacted $\mathrm{CO}$ estimated from Fig. 1e in the same way. The conversion efficiency from adsorbed $\mathrm{CO}$ to $\mathrm{CO}_{2}$ and the amounts of adsorbed $\mathrm{CO}$ and $\mathrm{O}$ for each cluster size are summarized in Fig. If and Supplementary Fig. 3a, b, respectively. Interestingly, $\mathrm{CO}_{2}$ is produced at the same temperature of $\sim 300 \mathrm{~K}$ for all cluster sizes (Supplementary Note 1). This result indicates that the same activation barrier exists for each Pt cluster (Supplementary Note 2 and Supplementary Fig. 4). We confirmed that the morphology and size of the Pt clusters were maintained after oxidation at room temperature (Supplementary Fig. 5). Without Pt clusters, no $\mathrm{CO}_{2}$ was produced (Supplementary Fig. 2). The Pt clusters on $\mathrm{Al}_{2} \mathrm{O}_{3}$ were thermally stable at temperatures up to $600 \mathrm{~K}$ under ultrahigh vacuum (UHV) conditions (Supplementary Fig. 6), suggesting that the cluster size is maintained in the TPR experiments.

As the number of $\mathrm{Pt}$ atoms in the cluster is controlled using a mass filter, the exact number of $\mathrm{Pt}$ atoms in each cluster is known. By contrast, the shape of the cluster can only be confirmed by 
a

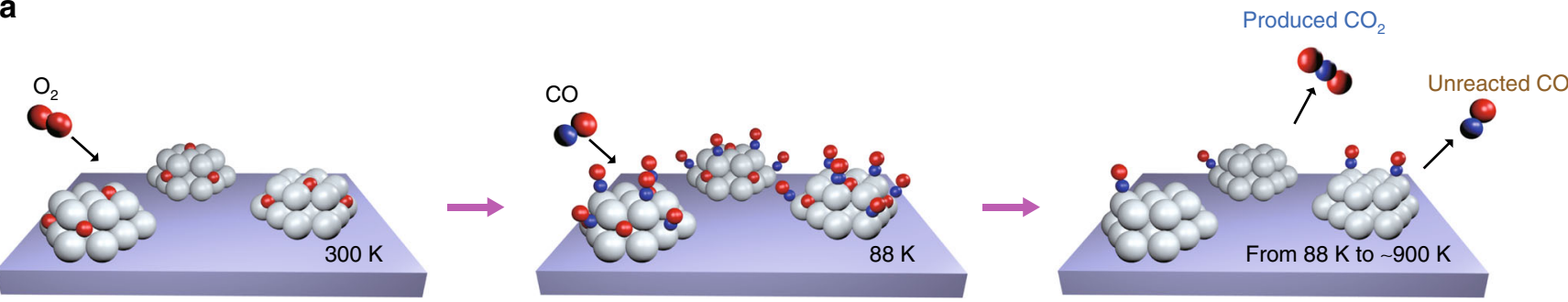

b

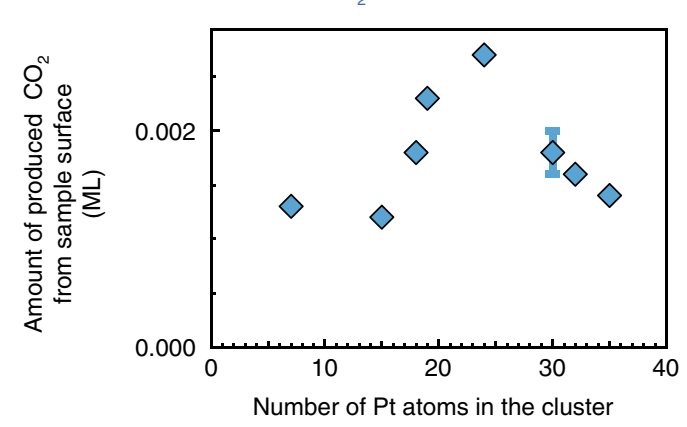

d
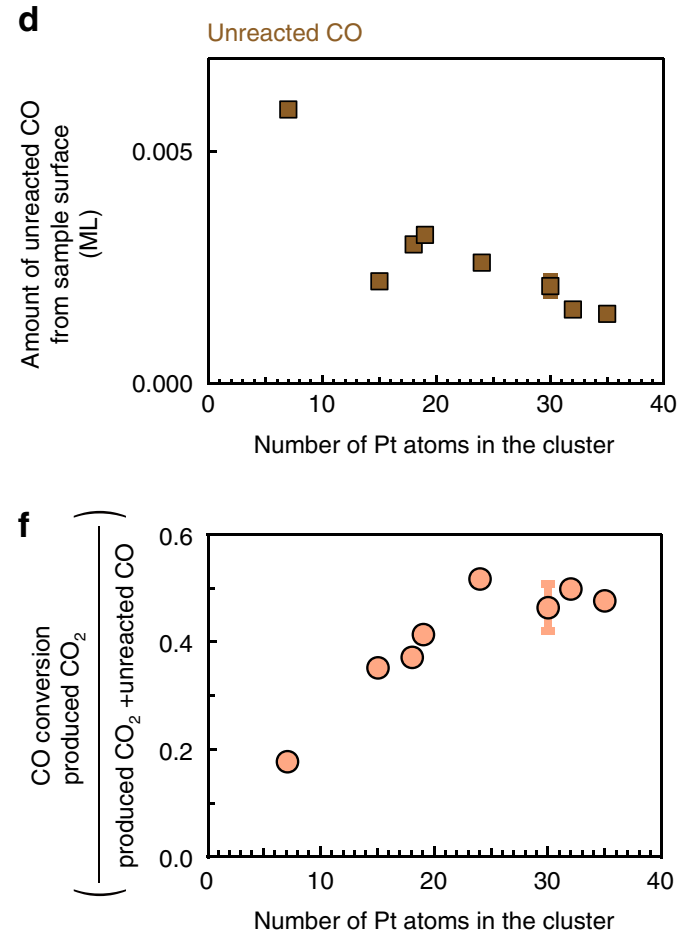

C Produced $\mathrm{CO}_{2}$

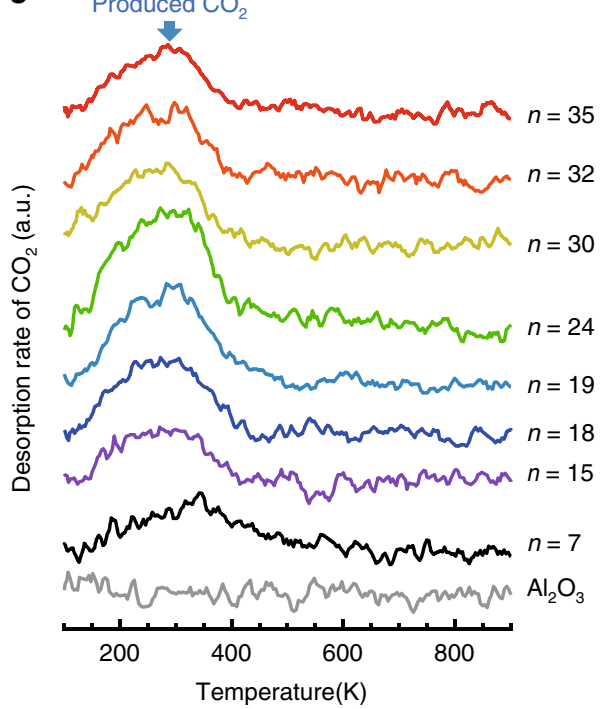

e

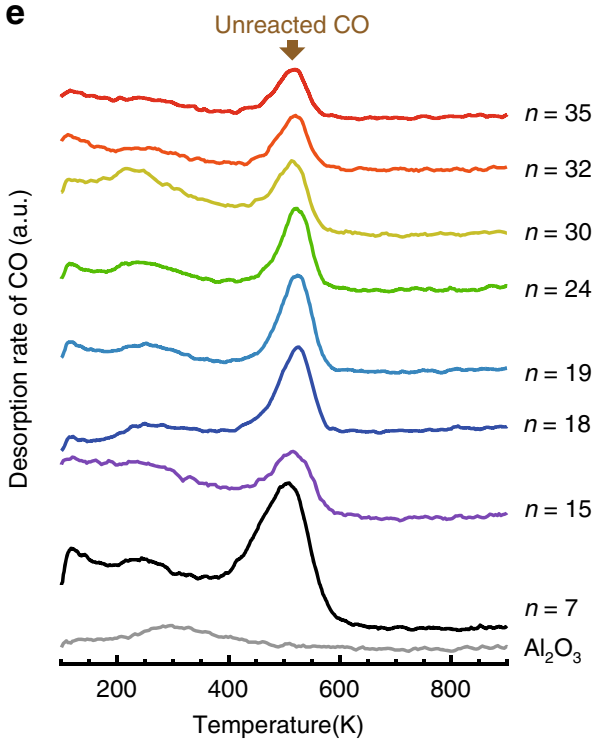

Fig. 1 CO oxidation activity of mass-selected $\mathbf{P t}_{\mathbf{n}}$ clusters on $\mathbf{A l}_{\mathbf{2}} \mathbf{O}_{\mathbf{3}}$. a Overview of the $\mathrm{CO}_{2}$ temperature-programmed reaction (TPR) measurements. The $\mathrm{Pt}_{n}$-deposited surfaces were exposed to $1000 \mathrm{~L}$ of ${ }^{18} \mathrm{O}_{2}$ at $300 \mathrm{~K}$ to saturate the $\mathrm{Pt}_{n}$ clusters with ${ }^{18} \mathrm{O}$ atoms, followed by saturation adsorption of ${ }^{13} \mathrm{CO}$ at $88 \mathrm{~K}$, and finally the TPR measurement was performed. The Pt coverage was $0.02 \mathrm{ML}$. b Amount of produced $\mathrm{CO}_{2}$ from sample surface with mass-selected Pt single clusters relative to the number of $\mathrm{Pt}$ atoms in the cluster. The error bars were determined from multiple measurements on a single cluster size. c $\mathrm{CO}_{2}$ TPR spectra $(\mathrm{m} / \mathrm{z}=47)$ over $\mathrm{Pt}_{n} / \mathrm{Al}_{2} \mathrm{O}_{3}$. The number of produced $\mathrm{CO}_{2}$ molecules was estimated by integrating the intensity between 100 and $500 \mathrm{~K}$. d Amount of unreacted $\mathrm{CO}$ molecules relative to the number of Pt atoms in the cluster. e CO TPR spectra $(\mathrm{m} / z=29)$ over Pt $n / \mathrm{Al}_{2} \mathrm{O}_{3}$. $\mathbf{f} \mathrm{CO}$ conversion (ratio of produced $\mathrm{CO}_{2}$ molecules to adsorbed $\mathrm{CO}$ molecules) as a function of the number of Pt atoms in the cluster. The error bars in $\mathbf{b}$, $\mathbf{d}$, and f are standard deviation. Source data are provided as a Source Data file. 

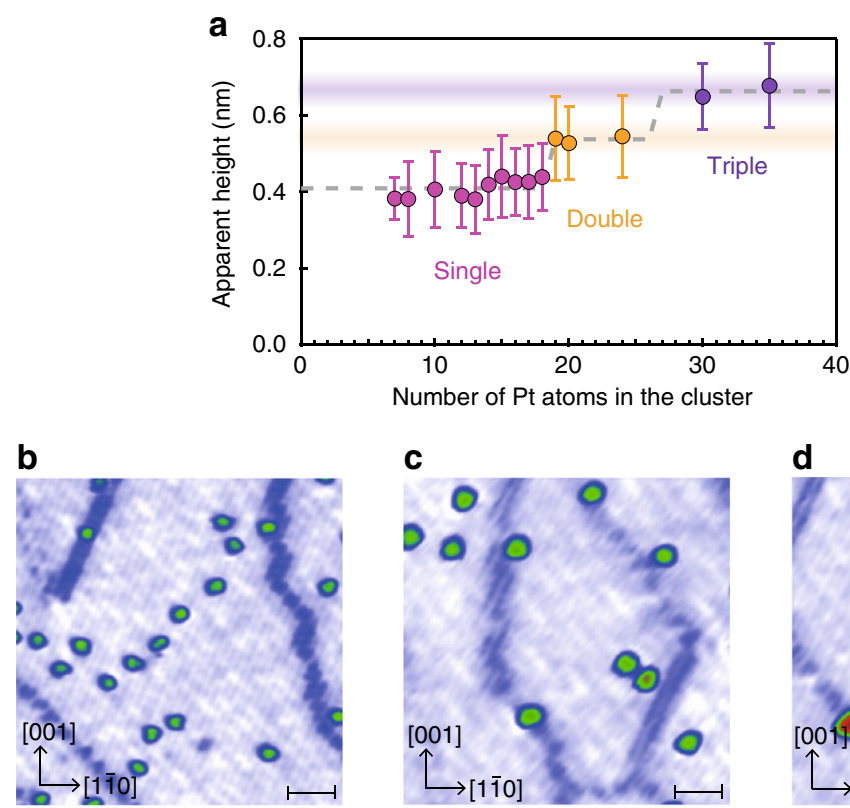

C

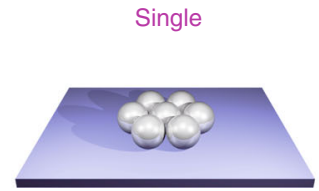

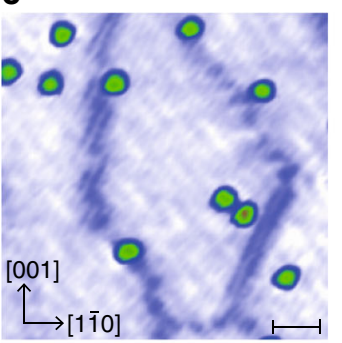

Double

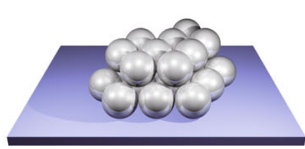

d
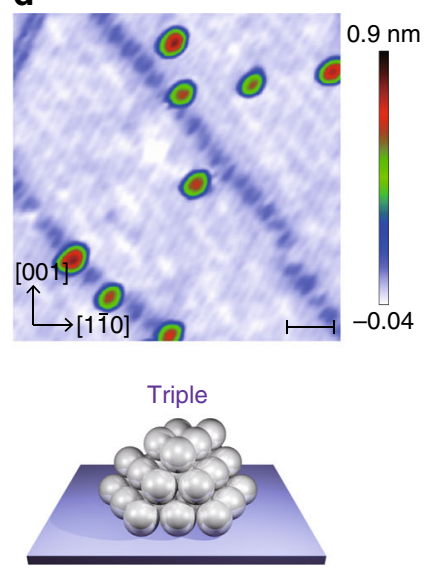

Fig. 2 Morphologies of mass-selected $\mathbf{P t}_{\boldsymbol{n}}$ clusters on $\mathbf{A l}_{\mathbf{2}} \mathbf{O}_{\mathbf{3}}$. a Size dependency of average cluster height on $\mathrm{Al}_{2} \mathrm{O}_{3}$. The error bars and dashed lines represent the standard deviations and morphologies simulated using the modified bond-additivity model. Source data are provided as a Source Data file. b-d Scanning tunnelling microscopy (STM) images of $\mathrm{Pt}_{n} / \mathrm{Al}_{2} \mathrm{O}_{3}$ for $n=7$ (b), $n=24$ (c), and $n=35$ (d) (scale bars: 5 nm). The STM measurements were performed at $78 \mathrm{~K}$.

direct imaging 28 . Thus we performed a scanning tunnelling microscopy (STM) analysis of the $\mathrm{Pt}_{n}$ clusters on the $\mathrm{Al}_{2} \mathrm{O}_{3}$ support. More than 50 clusters were analysed statistically to estimate the frequency of Pt clusters of different sizes ( 2000 clusters in total). The Pt clusters exhibit a single layer up to $n=$ 18 and then a double layer is observed up to $n=30$, at which point a triple layer appears (Fig. 2a; see also Supplementary Fig. 7). Figure $2 \mathrm{~b}-\mathrm{d}$ show representative STM images of $\mathrm{Pt}_{n}$ clusters on the $\mathrm{Al}_{2} \mathrm{O}_{3}$ support at $n=7,24$, and 35 , in which single, double, and triple layers of $\mathrm{Pt}_{n}$ clusters appear. Interestingly, the amount of produced $\mathrm{CO}_{2}$ (Fig. 1b) increases upon changing from single- to double-layer clusters and then decreases when the third layer is added, which indicates an apparent correlation between the $\mathrm{CO}$ oxidation activity and the cluster height. However, we observed no correlation between the amount of produced $\mathrm{CO}_{2}$ and the number of surface-exposed $\mathrm{Pt}$ atoms in $\mathrm{Pt}_{n} / \mathrm{Al}_{2} \mathrm{O}_{3}$ (Supplementary Fig. 8).

Position of cationic Pt atoms within clusters. Double-layer Pt clusters of $\sim 1 \mathrm{~nm}$ in diameter had higher $\mathrm{CO}$ oxidation activities than single- and triple-layer clusters on $\mathrm{Al}_{2} \mathrm{O}_{3}$. This result is counterintuitive because single-layer clusters have a larger number of surface-exposed $\mathrm{Pt}$ atoms than the double- and triple-layer cluster and thus should show higher CO oxidation activities. Therefore, it is likely that some of the Pt atoms in the first layer of the cluster are catalytically less active or have different chemical states.

IRAS analyses have revealed that ${ }^{13} \mathrm{CO}$ bound to lowcoordinated neutral $\mathrm{Pt}$ (for example, at the nanocluster edge) exhibits a peak at approximately $2000-2029 \mathrm{~cm}^{-114,16,29,30}$, and many studies have confirmed that adsorption on the oxidized species results in a peak at approximately $2032-2081 \mathrm{~cm}^{-1}$. Thus
IRAS is suitable for judging the chemical states (we note that an exception has been reported for adsorption on single $\mathrm{Pt}$ atoms, resulting in a peak at $2012 \mathrm{~cm}^{-1}$, as shown in Supplementary Fig. 9 and Supplementary Table 1).

We collected IRAS spectra for the prepared samples before and after exposure to ${ }^{13} \mathrm{CO}$ to observe the peak corresponding to the ${ }^{13} \mathrm{CO}$ stretching mode. This method, known as the $\mathrm{CO}$ probe method, is commonly used to investigate the chemical states of $\mathrm{Pt}^{16-19}$. It should be noted that at low temperatures (herein, $88 \mathrm{~K}$ ) $\mathrm{CO}$ cannot adsorb on the bare $\mathrm{Al}_{2} \mathrm{O}_{3}$ support, only on $\mathrm{Pt}^{31}$, and that the coordination number and the chemical state of $\mathrm{Pt}$ both affect the CO stretching mode.

Figure 3a shows the IRAS spectra for various sizes of Pt clusters on $\mathrm{Al}_{2} \mathrm{O}_{3}$. We observed a peak at $2020 \mathrm{~cm}^{-1}$ for the $\mathrm{Pt}_{n}$ clusters with $n=19-32$, indicating the existence of neutral Pt atoms. As the cluster size decreased, a small peak appeared at approximately $2044 \mathrm{~cm}^{-1}$ for $n=19$ and this peak became prominent at $n=7$. A corresponding decrease in the peak at $2020 \mathrm{~cm}^{-1}$ indicated that the ratio of the number of oxidized $\mathrm{Pt}$ atoms to the number of neutral Pt atoms increased as the cluster size decreased. The two IRAS peaks observed at 2020 and $2044 \mathrm{~cm}^{-1}$ can be attributed to neutral and cationic Pt atoms, respectively, in accordance with the results of previous studies (Supplementary Fig. 9). The IRAS peak for $\mathrm{Pt}(\mathrm{II})$ on $\mathrm{Al}_{2} \mathrm{O}_{3}$ is known to appear at wavenumbers $>2060 \mathrm{~cm}^{-1}$ owing to the isotopic shift ${ }^{17,32}$; thus it is reasonable to assume that oxidized Pt bears only a slight positive charge (herein, this $\mathrm{Pt}$ is referred to as cationic $\mathrm{Pt}$ ). To further verify this assignment, we analysed $\mathrm{Pt}_{7} / \mathrm{Al}_{2} \mathrm{O}_{3}$ using $\mathrm{X}$-ray photoelectron spectroscopy (XPS), which demonstrated that $\mathrm{Pt}$ within the $\mathrm{Pt}_{7}$ cluster has an oxidation state between $\mathrm{Pt}(0)$ and $\mathrm{Pt}(\mathrm{II})$ (Supplementary Fig. 10). 

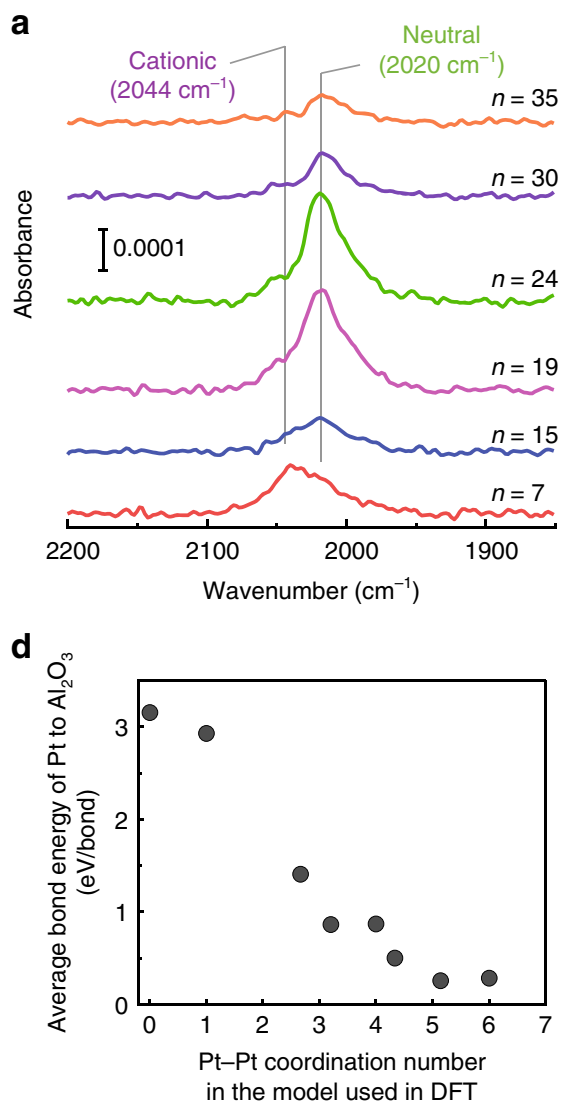

b

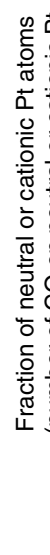

e

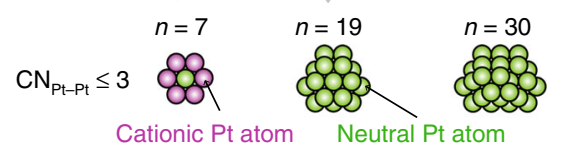

$\mathrm{CN}_{\mathrm{Pt}-\mathrm{Pt}} \leq 4$

88

$\mathrm{CN}_{\mathrm{Pt}-\mathrm{Pt}} \leq 5 \quad 88$ c

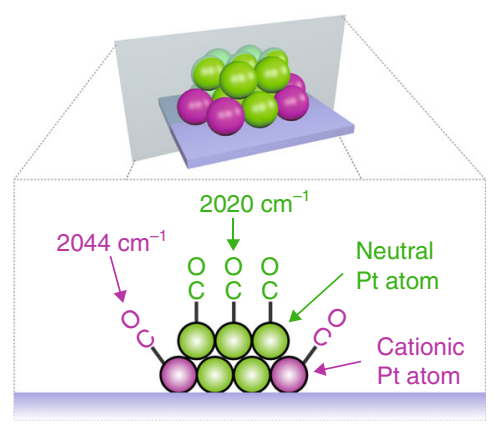

g

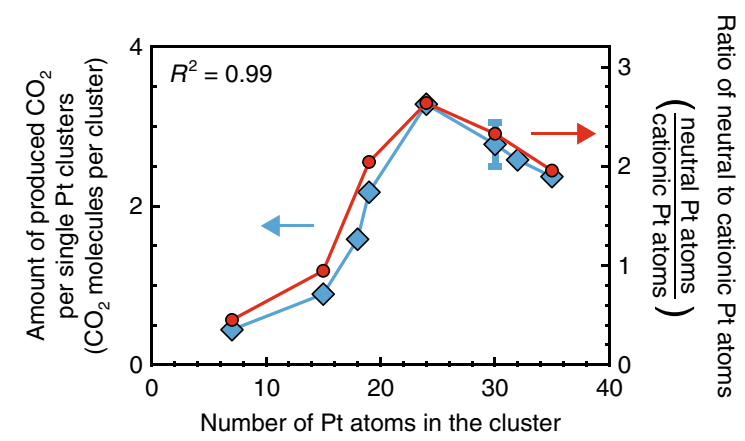

Fig. 3 Chemical states of $\mathbf{P t}$ and their effect on $\mathbf{C O}$ oxidation activity. a Infrared reflection absorption spectroscopy (IRAS) spectra of ${ }^{13} \mathrm{CO}$ adsorbed on $\mathrm{Pt}_{n} / \mathrm{Al}_{2} \mathrm{O}_{3}$. b Fraction of neutral and cationic Pt atoms estimated from IRAS spectra. Circles and squares represent fraction of neutral and cationic atoms, respectively. c Schematic diagram illustrating the adsorption of $\mathrm{CO}$ on a Pt cluster. d Average bond energy of $\mathrm{Pt}_{-} \mathrm{Al}_{2} \mathrm{O}_{3}$ determined using density functional theory (DFT) calculations. A linear increase in the bond energy between Pt and $\mathrm{Al}_{2} \mathrm{O}_{3}$ is observed as $\mathrm{CN}_{\mathrm{Pt}} \mathrm{Pt}$ is decreased from 5 to 0 . The structural models used for these calculations are shown in Supplementary Fig. 12a. e Schematic diagram of clusters showing the location of cationic Pt atoms for different Pt coordination numbers. $\mathbf{f}$ Fraction of cationic Pt atoms in the cluster. Good agreement with the experimental data (purple squares) is observed for $X=5$ (open squares). $X=3,4$, and 6 are represented as open circles, open triangles, and open diamonds, respectively. $g$ Relationship between the amount of produced $\mathrm{CO}_{2}$ per Pt single clusters (circles) and the ratio of neutral to cationic Pt atoms (diamonds). The coefficient of determination ( $R^{2}$ ) between these parameters was calculated to be 0.99 using the least mean square method. The error bar in $\mathbf{g}$ is standard deviation. Source data are provided as a Source Data file.

Figure $3 \mathrm{~b}$ shows the atomic fractions of the two types of $\mathrm{Pt}$ atoms as functions of the number of $\mathrm{Pt}$ atoms in the cluster (Supplementary Fig. 11 and Supplementary Note 3, which describes the method employed for estimating the atomic fractions). A steep decrease in the atomic fraction of cationic Pt (or increase in the fraction of neutral $\mathrm{Pt}$ ) is observed in the singlelayer cluster region, and this decrease levels off in the double- and triple-layer cluster regions. This result suggests that cationic Pt atoms exist predominantly in the first layer of $\mathrm{Pt}$ clusters, presumably at the perimeter of the cluster (Fig. 3c). To elucidate the exact position of cationic Pt atoms within the clusters, we hypothesized that under-coordinated $\mathrm{Pt}$ atoms bind to the support surface more strongly and consequently become cationic. This suggestion is reasonable because the coordination number of adsorbates has been shown to affect the adsorption energy ${ }^{33}$ and because charge transfer from $\mathrm{Pt}$ to $\mathrm{Al}_{2} \mathrm{O}_{3}$ has been demonstrated $^{34}$. To verify this hypothesis, we theoretically calculated the total binding energy of each Pt cluster on $\mathrm{Al}_{2} \mathrm{O}_{3}$ (Supplementary Fig. 12 and Supplementary Note 4). As hypothesized, these calculations revealed that a lower coordination number for the $\mathrm{Pt}$ 
atom results in a stronger bond with $\mathrm{Al}_{2} \mathrm{O}_{3}$ (Fig. 3d). This tendency can be understood intuitively from the principle of bond order conservation ${ }^{35}$ and can also be explained from the results reported for $\mathrm{Ag}$ on $\mathrm{MgO}(100)$, where the adhesion energy (or bond energy) increased with decreasing Ag particle size ${ }^{36}$.

The atomic fraction of cationic Pt atoms with respect to the number of $\mathrm{Pt}$ atoms in the cluster (Fig. $3 \mathrm{~b}$ ) should match well with that obtained from the model in which the neutral and cationic Pt atoms were correctly assigned by assuming that the intensities of the IRAS peaks at 2020 and $2044 \mathrm{~cm}^{-1}$ are proportional to the number of neutral and cationic Pt atoms, respectively. In other words, if we can develop a model that matches well with the IRAS results, we can deduce the coordination number that results in the atoms becoming cationic. To clarify this point, we constructed several structural models by manually assigning which $\mathrm{Pt}$ atoms were cationic. We assumed that all $\mathrm{Pt}$ atoms in the cluster were cationic if the coordination number of $\mathrm{Pt}$ to neighbouring $\mathrm{Pt}$ atoms $\left(\mathrm{CN}_{\mathrm{Pt}-\mathrm{Pt}}\right)$ was below a certain number, $X$ (Fig. 3e), and searched for the $X$ that provided a match to the experimental IRAS data. At $X=5$, the curves matched the IRAS data reasonably well (Fig. 3f), which indicated that $\mathrm{Pt}$ atoms with $\mathrm{CN}_{\mathrm{Pt}-\mathrm{Pt}}$ values $<5$, located at the perimeter of the cluster, behaved as cationic atoms.

Effect of Pt chemical states on CO oxidation activity. The analysis performed thus far revealed two important findings. First, there is no correlation between the amount of produced $\mathrm{CO}_{2}$ and the number of surface-exposed $\mathrm{Pt}$ atoms in $\mathrm{Pt}_{n} / \mathrm{Al}_{2} \mathrm{O}_{3}$. Second, cationic $\mathrm{Pt}$ appears at the edges of the first layer of the $\mathrm{Pt}$ clusters and the number of cationic Pt atoms increases with a decrease in the Pt cluster size.

Given that CO molecules adsorb on both neutral and cationic $\mathrm{Pt}$ atoms, the total amount of adsorbed $\mathrm{CO}$ should be proportional to the total number of surface-exposed neutral and cationic $\mathrm{Pt}$ atoms $\left(\theta_{\mathrm{CO}} \propto N_{\mathrm{n}}+N_{\mathrm{c}}\right)$. As $\mathrm{O}$ has a high electronegativity, it is reasonable to assume that $\mathrm{O}$ prefers to adsorb on neutral $\mathrm{Pt}$ atoms $\left(\theta_{\mathrm{O}} \propto N_{\mathrm{n}}\right)$. Thus the ratio of the amount of adsorbed $\mathrm{CO}$ to $\mathrm{O}$, that is, $\theta_{\mathrm{CO}} / \theta_{\mathrm{O}}$, can be expressed by Eq. (2):

$$
\theta_{\mathrm{CO}} / \theta_{\mathrm{O}} \propto\left(N_{\mathrm{n}}+N_{\mathrm{c}}\right) / N_{\mathrm{n}}=1+N_{\mathrm{c}} / N_{\mathrm{n}}
$$

In fact, $\theta_{\mathrm{CO}} / \theta_{\mathrm{O}}$ was matched well with $\left(N_{\mathrm{n}}+N_{\mathrm{c}}\right) / N_{\mathrm{n}}$ as shown in Supplementary Fig. 3c. For CO oxidation, equivalent amounts of $\mathrm{CO}$ and $\mathrm{O}$ would result in the $\mathrm{CO}$ oxidation activity being maximized when $N_{\mathrm{c}} / N_{\mathrm{n}}$ is zero. In other words, the Pt cluster with the maximum $N_{n} / N_{c}$ value will show the highest $C O$ oxidation activity, and thus it will produce the largest amount of $\mathrm{CO}_{2}$. Figure $3 \mathrm{~g}$ shows the ratio of neutral to cationic $\mathrm{Pt}$ atoms $\left(N_{\mathrm{n}} / N_{\mathrm{c}}\right)$ estimated by IRAS and the amount of produced $\mathrm{CO}_{2}$ measured using TPR as functions of the number of Pt atoms in the cluster. As expected, we found a strong correlation between the $N_{\mathrm{n}} / N_{\mathrm{c}}$ and the amount of produced $\mathrm{CO}_{2}$ (the $R^{2}$ value estimated by the least mean square method was 0.99). This observation suggests that cationic Pt has a low oxygen affinity, which explains why the smallest cluster does not show the highest CO oxidation activity in this study.

This strong correlation would be practically useful for estimating the $\mathrm{CO}$ oxidation activity for different cluster sizes if the thermodynamically most stable Pt atomic arrangement could be determined for each cluster size and enabled to calculate $N_{\mathrm{n}}$ and $N_{c}$.

Thermodynamically stable Pt cluster morphologies. The most stable arrangement can be determined by searching for the cluster model that gives the highest binding energy $\left(E_{\mathrm{bd}}\right)$, as calculated by summing the bond energies of each $\mathrm{Pt}-\mathrm{Pt}$ and $\mathrm{Pt}-$ support bond (Eq. (3) $)^{36-38}$.

$$
E_{\mathrm{bd}}=\sum_{i=1}^{N_{\mathrm{Pt}-\mathrm{Pt}}} E_{\mathrm{Pt}-\mathrm{Pt}, i}+\sum_{j=1}^{N_{\mathrm{Pt}-\mathrm{S}}} E_{\mathrm{Pt}-\text { support }, j},
$$

where $E_{\mathrm{Pt}-\mathrm{Pt}, i}$ and $E_{\mathrm{Pt}-\text { support }, j}$ are the bond energies of $i$ th $\mathrm{Pt}-\mathrm{Pt}$ bond and the $j$ th $\mathrm{Pt}$-support bond, respectively. $N_{\mathrm{Pt}-\mathrm{Pt}}$ and $N_{\mathrm{Pt}-\text { support }}$ represent the numbers of $\mathrm{Pt}$-Pt bonds and $\mathrm{Pt}$-support bonds, respectively (Fig. 4a). This method is known as BAM. Although the conventional BAM assumes constant bond energies for both Pt-Pt and Pt-support bonds, an enhancement in bond strength from the bulk to under-coordinated Pt atoms $\left(\mathrm{CN}_{\mathrm{Pt}-\mathrm{Pt}} \leq 5\right)$ should be taken into account. Thus we implemented this enhancement into the BAM as follows. First, all the possible cluster models that exhibited individual single, double, triple, and quadruple layers for different cluster sizes were constructed (Fig. 4b). Second, the binding energies for all the models were calculated by summing the $\mathrm{Pt}$-support bond energies for individual $\mathrm{Pt}$ atoms that have different coordination numbers in the cluster (Fig. 4c). Finally, the binding energy of each model was plotted as a function of the number of Pt atoms in the cluster (Fig. 4d), and the transitions from single to double and from double to triple layers were determined.

To estimate the binding energy, it is necessary to calculate all the individual bond energies in the cluster; for this purpose, the linear function shown in Supplementary Eq. (6), deduced by density functional theory (DFT) (Fig. 3d), was used. We assumed that the bond energy changed linearly as a function of the coordination number of the $\mathrm{Pt}$ atoms in the cluster. Consequently, two appropriate bond energies for $\mathrm{CN}_{\mathrm{Pt}-\mathrm{Pt}}=0$ and $\mathrm{CN}_{\mathrm{Pt}-\mathrm{Pt}}=5$ were assigned (Fig. 4c), and the slope and the intercept of Supplementary Eq. (6) were calculated. Subsequently, the coordination number of the Pt atom of interest in the cluster was incorporated into the equation, allowing determination of its bond energy. We repeated this process for all remaining $\mathrm{Pt}$ atoms in the cluster by assigning different bond energies at $\mathrm{CN}_{\mathrm{Pt}-\mathrm{Pt}}=0$ and 5 , until the transitions from single to double and from double to triple layers appeared at $n=18-19$ and at $n=24-30$ (Fig. 4d), respectively, as observed by STM (Fig. $2 \mathrm{a}$ ).

Consequently, we determined the binding energy of the $\mathrm{Pt}$ monomer, corresponding to $\mathrm{CN}_{\mathrm{Pt}-\mathrm{Pt}}=0$, to be $3.9 \mathrm{eV}$, whereas that for $\mathrm{CN}_{\mathrm{Pt}-\mathrm{Pt}}=5$ was determined to be $1.0 \mathrm{eV}(\sim 30 \%$ of the bond energy at $\left.\mathrm{CN}_{\mathrm{Pt}-\mathrm{Pt}}=0\right)$. For the Pt-Pt bond, the bulk Pt-Pt value of $0.98 \mathrm{eV}$ was used (see Supplementary Notes 5 and 6 and Supplementary Figs. 13-15). The reported binding energy of the $\mathrm{Pt}$ monomer calculated by DFT is $3.5 \mathrm{eV}^{25}$, which is in good agreement with our value $(3.9 \mathrm{eV})$.

Accordingly, we calculated the bond energy of each Pt-Pt and Pt-support bond with a different coordination number and constructed the most thermodynamically stable morphology for each cluster size.

Prediction of the CO oxidation activity of Pt clusters. Using the discovered relationship and our modified BAM method (Fig. 5a), it should be possible to predict the $\mathrm{CO}$ oxidation activities of different cluster sizes. Thus we first built the cluster models using the modified BAM. Two bond energies were used to consider the bond enhancement effect: $3.50 \mathrm{eV}$ for $\mathrm{CN}_{\mathrm{Pt}-\mathrm{Pt}}=0$, as previously calculated using $\mathrm{DFT}^{25}$, and $1.05 \mathrm{eV}(30 \%$ of $3.50 \mathrm{eV})$ for $\mathrm{CN}_{\mathrm{Pt}-\mathrm{Pt}}=5$, as calculated using Supplementary Eq. (6) for $\mathrm{Pt}_{n} / \mathrm{Al}_{2} \mathrm{O}_{3}$. Next, we calculated the ratio of neutral to cationic $\mathrm{Pt}$ atoms using these cluster models (Fig. 5b). The results were in excellent agreement with the amounts of $\mathrm{CO}_{2}$ produced for $\mathrm{Pt}_{n} / \mathrm{Al}_{2} \mathrm{O}_{3}$, which displayed a peak at a cluster size of $n=24$, confirming that it is possible to predict the optimum $\mathrm{Pt}$ cluster size for maximizing the $\mathrm{CO}$ oxidation activity. 
a

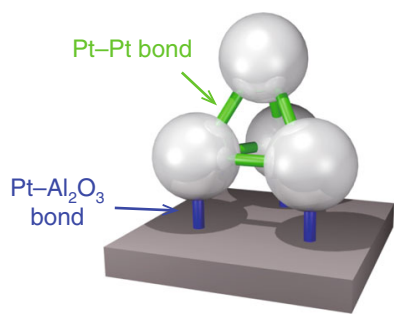

C

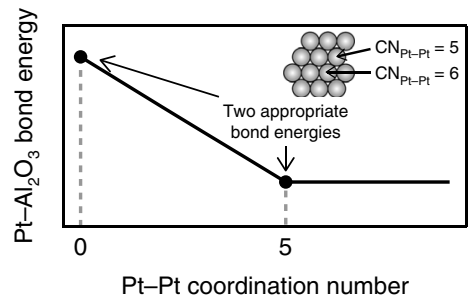

b

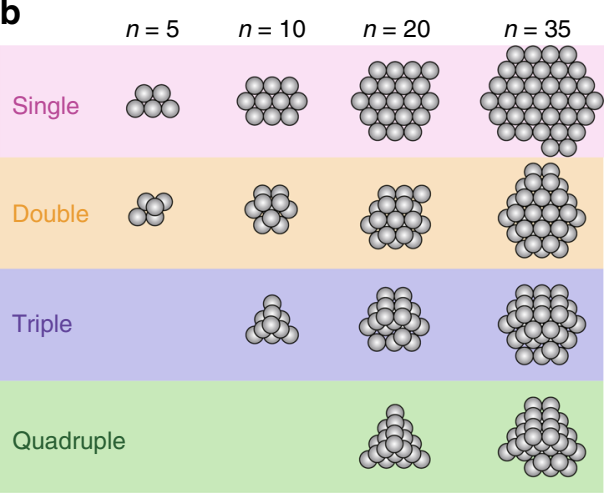

d

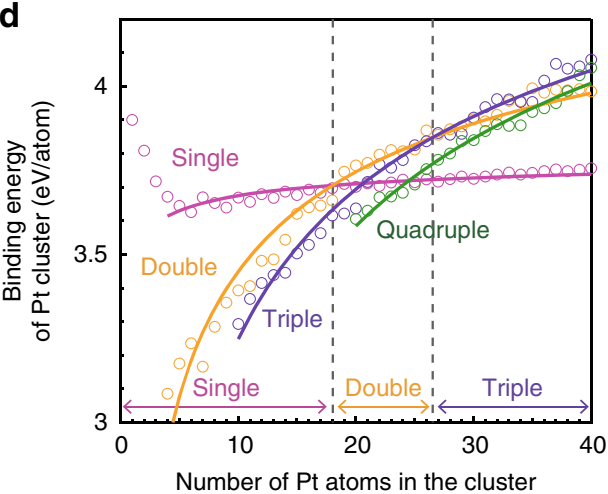

Fig. 4 Simulation of cluster morphologies using the bond-additivity model. a Schematic illustration of a double-layer $\mathrm{Pt}_{4} \mathrm{Cluster}$. The $\mathrm{Pt}-\mathrm{Pt}$ and $\mathrm{Pt}-\mathrm{Al}_{2} \mathrm{O}_{3}$ bonds are represented using green and blue lines, respectively. $\mathbf{b}$ Top view of the models for $\mathrm{Pt}_{n}$ structures for which binding energies were calculated using the bond-additivity model (BAM). The numbers of Pt-Pt and $\mathrm{Pt}_{-}-\mathrm{Al}_{2} \mathrm{O}_{3}$ bonds were counted based on these model structures. $\mathbf{c}$ Schematic illustration of the $\mathrm{Pt}-\mathrm{Al}_{2} \mathrm{O}_{3}$ bond energy as a function of the Pt-Pt coordination number, which was used to calculate the binding energies of the Pt $\mathrm{n}_{n}$ clusters using the $\mathrm{BAM}$. The arrows indicate the bond energies at $\mathrm{CN}_{\mathrm{Pt}-\mathrm{Pt}}=0$ and 5, which were used to calculate the slope and intercept of the linear function. $\mathbf{d}$ Binding energies of $\mathrm{Pt}_{n}$ clusters with single, double, triple, and quadruple layer (represented by pink, orange, blue, and green circles, respectively) calculated using the BAM as a function of cluster size. The two vertical dashed lines show the simulated sizes corresponding to morphological transitions from single to double layers $(n=18-19)$ and from double to triple layers $(n=26-27)$. Source data are provided as a Source Data file.

To further verify the feasibility of this method, which only uses the appropriate bond energy between the Pt monomer and the support, we estimated the $\mathrm{CO}$ oxidation activities for the $\mathrm{Pt}$ nanoclusters on a $\mathrm{TiO}_{2}$ surface. To construct the thermodynamically stable structures with our modified BAM, we used $2.4 \mathrm{eV}$, the reported bond energy between $\mathrm{Pt}$ monomers and $\mathrm{TiO}_{2}{ }^{39}$, as the bond energy for $\mathrm{CN}_{\mathrm{Pt}-\mathrm{Pt}}=0$ and $0.72 \mathrm{eV}$ for $\mathrm{CN}_{\mathrm{Pt}-\mathrm{Pt}}=5$, which is $30 \%$ of the bond energy at $\mathrm{CN}_{\mathrm{Pt}-\mathrm{Pt}}=0$. The bond energy for $\mathrm{CN}_{\mathrm{Pt}-\mathrm{Pt}}$ values between 2 and 4 were linearly interpolated. Similar to the $\mathrm{Pt}_{n} / \mathrm{Al}_{2} \mathrm{O}_{3}$ case, the calculated results showed a very good correlation with the experimentally obtained amounts of produced $\mathrm{CO}_{2}$ for $\mathrm{Pt}_{n} / \mathrm{TiO}_{2}$ (Fig. $5 \mathrm{c}$ and Supplementary Fig. 16). The clusters with 15-30 atoms, corresponding to diameters of $\sim 0.8-1.4 \mathrm{~nm}$, showed high CO oxidation activities. Such good agreement was not achieved without assuming the existence of cationic $\mathrm{Pt}$, indicating that cationic $\mathrm{Pt}$ atoms also exist in the clusters on $\mathrm{TiO}_{2}$. This finding is in line with the previous observation that the Pt $4 \mathrm{f}$ XPS peak is positioned between the peaks corresponding to oxidized $\mathrm{Pt}(\mathrm{II})$ and neutral $\mathrm{Pt}(0)^{11}$.

\section{Discussion}

In summary, the $\mathrm{CO}$ oxidation activities of mass-selected $\mathrm{Pt}$ nanocluster catalysts on two typical metal oxide supports were investigated. It was shown that $\mathrm{Pt}$ atoms become cationic when their coordination number to neighbouring $\mathrm{Pt}$ atoms is $<5$. Our IRAS analyses identified two different peaks corresponding to neutral and cationic $\mathrm{Pt}$, the latter of which bears a slightly positive charge. These cationic Pt atoms appear only in the first layer of the cluster and benefit from an enhancement in binding to the support surface. Although no correlation was observed between the $\mathrm{CO}$ oxidation activity and the total number of surfaceexposed Pt atoms, a strong correlation was found between the atomic ratio of the neutral to cationic $\mathrm{Pt}$ atoms in the cluster $\left(N_{n} / N_{c}\right)$ and the amount of produced $\mathrm{CO}_{2}$ for $\mathrm{Pt}_{n} / \mathrm{Al}_{2} \mathrm{O}_{3}$. We exploited this strong correlation to predict the cluster size that produces the largest amount of $\mathrm{CO}_{2}$ for $\mathrm{Pt}_{n} / \mathrm{TiO}_{2}$ by simulating the most stable morphologies for clusters with different numbers of atoms using our modified BAM and calculating the number of neutral and cationic Pt atoms manually. The simulated atomic ratio of the neutral to cationic $\mathrm{Pt}$ atoms was in good agreement with the amounts of produced $\mathrm{CO}_{2}$ for $\mathrm{Pt}_{n} / \mathrm{TiO}_{2}$ estimated experimentally from TPR measurements. From the point of view of utilization, smaller catalysts would be expected to perform better than larger ones; however, our findings revealed that this expectation is not always true because the substrate material affects catalysts with diameters in the sub-nanometre to few atoms range owing to the existence of under-coordinated atoms at the perimeter of the cluster. We note that differences exist between the catalysis conditions in practical and model catalyst systems; for example, the oxide support is usually large and nonconducting in real catalyst systems. Furthermore, the cluster morphology might change dynamically during the reaction, as observed in several recent studies ${ }^{40,41}$. Nonetheless, we believe 
a

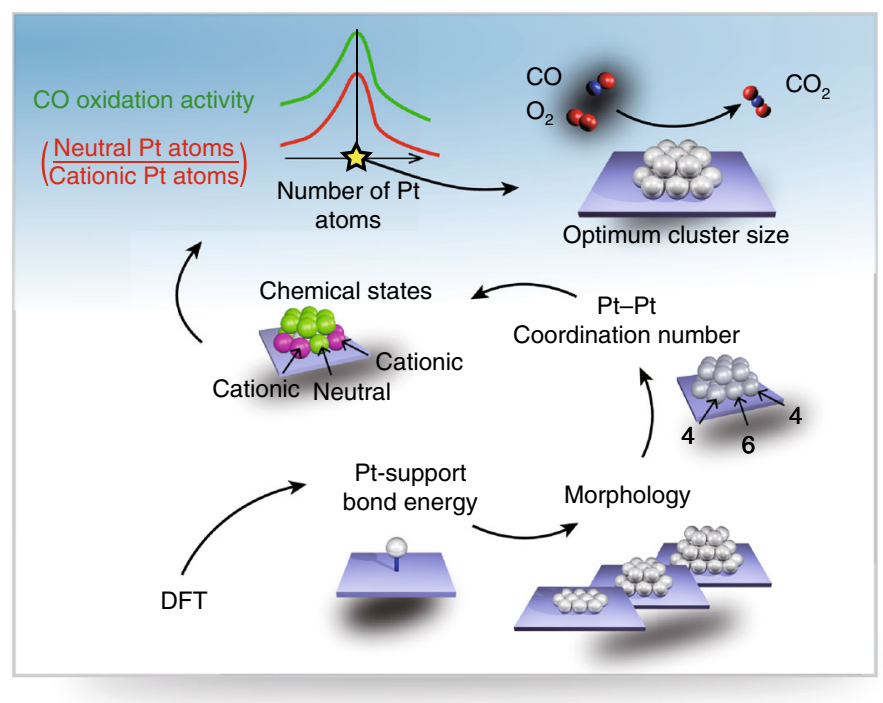

b
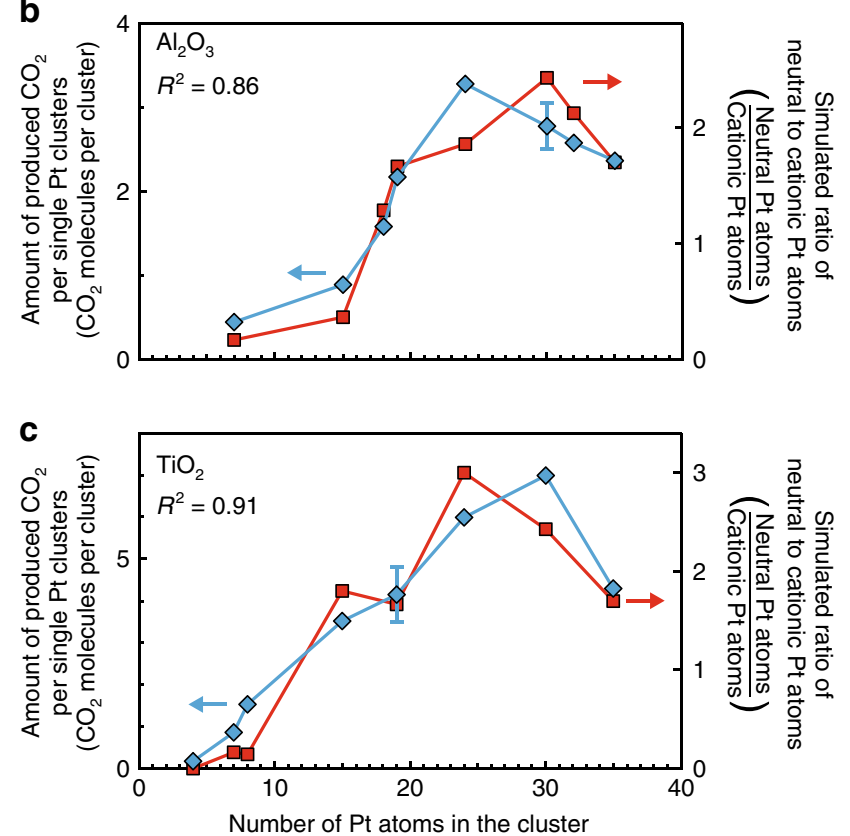

Fig. 5 Prediction of the optimum Pt cluster size for maximum CO oxidation activity. a Schematic diagram illustrating the protocol used for optimum Pt cluster size prediction. The process starts with a theoretical calculation of the binding energy for a Pt monomer on the support material. $\mathbf{b}, \mathbf{c}$ Comparison of the atomic ratios of neutral to cationic Pt atoms (red squares) with the amounts of $\mathrm{CO}_{2}$ produced for $\mathrm{Pt}_{n} / \mathrm{Al}_{2} \mathrm{O}_{3}(\mathbf{b})$ and $\mathrm{Pt} n / \mathrm{TiO}_{2}(\mathbf{c})(\mathrm{blue}$ diamonds). The error bars are standard deviation. Source data are provided as a Source Data file.

that the results presented in this study will be helpful for designing atomically dispersed nanostructured catalysts including single-atom and few-atom clusters or single-cluster catalysts, which have recently received considerable interest ${ }^{5,42-45}$.

\section{Methods}

Sample preparation. All experiments were performed in a UHV chamber $(<1 \times$ $\left.10^{-7} \mathrm{~Pa}\right)^{20}$. NiAl(110) substrates were oriented to within $0.1^{\circ}$ and $10 \mathrm{~mm}$ in diameter for the STM experiments and were $6 \mathrm{~mm} \times 10 \mathrm{~mm}$ in size for the TPR and IRAS experiments (Surface Preparation Laboratory). For the IRAS and TPR experiments, the temperature was monitored by a chromel-alumel ( $K$-type) thermocouple that was spot-welded to the side of the substrate. The clean $\mathrm{NiAl}(110)$ surface was prepared by several cycles of $\mathrm{Ar}^{+}$sputtering $(300 \mathrm{~K}, 20 \mathrm{~min})$ and annealing at $1300 \mathrm{~K}$ for $5 \mathrm{~min}$. The thin $\mathrm{Al}_{2} \mathrm{O}_{3}$ film was prepared by dosing $1800 \mathrm{~L}$ (Langmuir: $1 \times 10^{-6}$ Torr $\cdot \mathrm{s}$ ) of $\mathrm{O}_{2}$ at $600 \mathrm{~K}$, followed by annealing at $1100 \mathrm{~K}$ for $5 \mathrm{~min}^{23}$. The oxidation process was repeated more than three times to close open $\mathrm{NiAl}(110)$ patches in the film. We confirmed that the $\mathrm{Al}_{2} \mathrm{O}_{3}$ film covered the $\mathrm{NiAl}$ (110) surface fully by STM measurements. In addition, no IRAS peak characteristic of $\mathrm{CO}$ adsorbed on $\mathrm{NiAl}(110)$ was observed after exposure of the $\mathrm{Al}_{2} \mathrm{O}_{3} / \mathrm{NiAl}(110)$ surface to $\mathrm{CO}$ at $88 \mathrm{~K}$, clearly showing the absence of bare $\mathrm{NiAl}(110)$ regions. The $\mathrm{Al}_{2} \mathrm{O}_{3}$ film showed a characteristic IRAS peak corresponding to a crystalline $\mathrm{Al}_{2} \mathrm{O}_{3}$ film without amorphous components ${ }^{46}$, which is consistent with the observation of the low energy electron diffraction pattern of the crystalline $\mathrm{Al}_{2} \mathrm{O}_{3}$ surface ${ }^{23}$ with sharp spots and a low background intensity. The above data clearly show that our films are crystalline and fully cover the $\mathrm{NiAl}(110)$ surface.

The $\mathrm{TiO}_{2}(110)$ substrates, $10 \mathrm{~mm} \times 10 \mathrm{~mm}$ in size, were oriented to within $0.5^{\circ}$ for the STM experiments; for the TPR experiments, substrates of $6 \mathrm{~mm} \times 10 \mathrm{~mm}$ in size were used (Sinkosha Co., Ltd). For the TPR experiments, the temperature was monitored by a $K$-type thermocouple that was inserted into a slot at the side of the substrate with a Ta foil to ensure good thermal contact. The clean $\mathrm{TiO}_{2}(110)$ surface was prepared by several cycles of $\mathrm{Ar}^{+}$sputtering $(300 \mathrm{~K}, 10 \mathrm{~min})$ and annealing at $900-980 \mathrm{~K}$ for $10 \mathrm{~min}$. After the annealing process, the temperature was decreased to $300 \mathrm{~K}$ at a cooling rate of $1 \mathrm{~K} \mathrm{~s}^{-1}$. Based on the magnitude of the $\mathrm{OH}$ recombination peak in the temperature-programmed desorption (TPD) spectrum of $\mathrm{H}_{2} \mathrm{O}$, the coverage of surface oxygen vacancies was estimated to be $8 \%$ of the number of surface $\mathrm{Ti}^{4+}$ atoms $\left(5.2 \times 10^{14}\right.$ atoms $\left.\mathrm{cm}^{-2}\right)$, which is a typical value for standard surface preparation under $\mathrm{UHV}^{47}$.

$\mathrm{Pt}_{n}$ cluster ions were produced by a DC magnetron sputtering source (Angstrom Sciences, ONYX-1) and mass selected using a quadrupole mass filter (Extrel, MAX-16000) by sputtering a Pt target (Tanaka Kikinzoku Kogyo K.K., purity $>99.99 \%)^{20}$. Mass-selected $\mathrm{Pt}_{n}$ cluster ions were uniformly deposited on the surfaces at $300 \mathrm{~K}$ using the Lissajous scanning method ${ }^{48}$. The impact energy for cluster deposition was tuned to $<2 \mathrm{eV}$ atom ${ }^{-1}$ (soft-landing condition) by adjusting the bias voltage applied to the surface, where the impact energy was estimated using the retarding voltage method. The total amount of Pt deposited was determined from the integrated $\mathrm{Pt}_{n}{ }^{+}$neutralization current on the sample and was confirmed using STM and XPS. Small amounts of $\mathrm{Pt}_{n}$ clusters were deposited to avoid cluster aggregation in the deposition process. The Pt coverage was $0.02 \mathrm{ML}$ $\left(1 \mathrm{ML}=1.5 \times 10^{15}\right.$ atoms $\left.\mathrm{cm}^{-2}\right)$ for the TPR and IRAS experiments, and $<0.02 \mathrm{ML}$ for the STM experiments, where $>90 \%$ of the deposited clusters were adsorbed without aggregation ${ }^{21}$.

TPR experiments. To investigate the catalytic reaction of adsorbed species on the $\mathrm{Pt}_{n}$ clusters, we used isotopically labelled ${ }^{18} \mathrm{O}_{2}$ (Sigma-Aldrich Co., isotopic purity $=97 \%$ ) and ${ }^{13} \mathrm{CO}$ (Cambridge Isotope Laboratories, Inc., isotopic purity $=99 \%$ ). These gases were introduced through a pulse gas dosing system onto the sample surface, and the purity of each gas was checked using mass spectrometry. For the TPR experiments, the model catalyst samples were first exposed to $1000 \mathrm{~L}$ of ${ }^{18} \mathrm{O}_{2}$ at $300 \mathrm{~K}$ to saturate the $\mathrm{Pt}_{n}$ cluster surface by atomic oxygen, followed by saturation adsorption of ${ }^{13} \mathrm{CO}$ at $88 \mathrm{~K}$. Since the temperature in a catalytic converter in diesel combustion engines is typically above $\sim 550 \mathrm{~K}$, and the concentration of $\mathrm{O}_{2}$ is much higher than that of $\mathrm{CO}$ molecules, which desorb from the Pt catalyst surface at $\sim 500 \mathrm{~K}$, the surface of the Pt catalyst would be covered by $\mathrm{O}_{2}$ during $\mathrm{CO}$ oxidation. To mimic this situation, we pre-adsorbed $\mathrm{O}_{2}$ before adsorbing $\mathrm{CO}$, and we investigated the catalyst activity by TPR measurements. During the TPR measurements, the sample temperature was ramped at a rate of $3.5 \mathrm{~K} \mathrm{~s}^{-1}$ and desorbed molecules were detected using a quadrupole mass spectrometer (QMS, Pfeiffer, PrismaPlus QMG220M1). The ionization region was enclosed in a small glass envelope (Feulner cup) with a small opening ( $3 \mathrm{~mm}$ in diameter), and the crystal surface was placed in front of this opening at a distance of $1 \mathrm{~mm}$. The mass spectrometer sensitivity was calibrated by measuring the TPD spectrum of $(2 \times 2)$ $\mathrm{O} / \mathrm{Pt}(111)$ for every experiment. The area intensities for $\mathrm{CO}$ and $\mathrm{CO}_{2}$ coverages were analysed as follows: we collected $\geq 10$ data points measured from $\leq 100 \mathrm{~K}$ and $\geq 500 \mathrm{~K}$ to determine the background level (Supplementary Fig. 17 and Supplementary Note 7 ). The $\mathrm{CO}$ and $\mathrm{CO}_{2}$ coverages were estimated by comparing the area intensities of the TPD and TPR spectra with those of $c(4 \times 2) \mathrm{CO} / \mathrm{Pt}(111)$ $(0.50 \mathrm{ML}$ of $\mathrm{CO})$ and $\mathrm{CO}+\mathrm{O} / \mathrm{Pt}(111)$ at the saturation coverage $\left(0.25 \mathrm{ML}\right.$ of $\left.\mathrm{CO}_{2}\right)$. Background ${ }^{12} \mathrm{CO}$ could be adsorbed on the Pt clusters if the prepared sample is not swiftly investigated and if the surface is exposed for a long time in the UHV chamber. It should be possible to estimate the amount of ${ }^{12} \mathrm{CO}$ molecules to which the sample was exposed based on the time of exposure to background ${ }^{12} \mathrm{CO}$ (or the time required to prepare the samples and record the IRAS and TPD measurements, which is $\sim 77 \mathrm{~min})$ and its partial pressure $\left(\sim 1.7 \times 10^{-9} \mathrm{~Pa}\right)$. In our experiment, the ${ }^{12} \mathrm{CO}$ exposure amount was estimated to be $<0.1 \mathrm{~L}\left(1 \mathrm{~L}=1.33 \times 10^{-4} \mathrm{~Pa} \cdot \mathrm{s}\right)$, which is quite low. 
To quantify the amount of background ${ }^{12} \mathrm{CO}$ adsorbed on the Pt clusters, we exposed the Pt-cluster-deposited $\mathrm{Al}_{2} \mathrm{O}_{3}$ to ${ }^{13} \mathrm{CO}$ and performed TPD and IRAS measurements for both ${ }^{12} \mathrm{CO}$ and ${ }^{13} \mathrm{CO}$ (Supplementary Fig. 18). Adsorbed ${ }^{12} \mathrm{CO}$ and ${ }^{13} \mathrm{CO}$ were observed to desorb at $\sim 500 \mathrm{~K}$, and by integrating the intensity of their peaks, we confirmed that the fraction of ${ }^{13} \mathrm{CO}$ was $>0.9$ for all the prepared $\mathrm{Pt}$ cluster sizes, as shown in Supplementary Fig. 18b. Thus we conclude that the effect of adsorbed background ${ }^{12} \mathrm{CO}$ is minimal, which is also supported by the IRAS spectra, in which the stretching-vibrational modes of ${ }^{12} \mathrm{CO}$ at 2090 and $2066 \mathrm{~cm}^{-1}$ were not observed, as indicated in grey in Supplementary Fig. 18c.

We detected no $\mathrm{O}_{2}$ desorption during the TPR measurements, as in a previous report ${ }^{49}$. Thus, based on the previous report, the $\mathrm{O}$ coverage was calculated by assuming that all the adsorbed $\mathrm{O}$ was consumed by $\mathrm{CO}$ during the reaction (Supplementary Fig. 3$)^{49}$.

Desorption rates of $\mathrm{CO}$ and $\mathrm{CO}_{2}$ from the sample exposed to ${ }^{13} \mathrm{CO}$ and ${ }^{18} \mathrm{O}_{2}$ were estimated by measuring the corresponding ion currents using QMS, whereby the sample surface was heated at a constant rate $\left(3.5 \mathrm{~K} \mathrm{~s}^{-1}\right)$ and ion current is continuously monitored.

Scanning tunnelling microscopy. STM measurements were performed at $78 \mathrm{~K}$ using a low-temperature scanning tunnelling microscope (Omicron $\mathrm{GmbH})$ with a Nanonis controller (SPECS Zurich GmbH) and electrochemically etched tungsten tips. The STM images of $\mathrm{Pt}_{n} / \mathrm{Al}_{2} \mathrm{O}_{3}$ were taken at a positive sample bias $\left(V_{\mathrm{s}}\right)$ of $3.5 \mathrm{~V}$ and a tunnelling current $\left(I_{\mathrm{t}}\right)$ of $0.1 \mathrm{nA}$ and those of $\mathrm{Pt}_{n} / \mathrm{TiO}_{2}$ were taken at $V_{\mathrm{s}}$ of $1-3 \mathrm{~V}$ and $I_{\mathrm{t}}$ of $0.05-0.1 \mathrm{nA}$. To estimate the height of the sample from the STM measurements, we calibrated the height with respect to a single atomic step on $\mathrm{NiAl}$ under the same scanning conditions (see also Supplementary Fig. 7b and Supplementary Note 8).

Infrared reflection absorption spectroscopy. IRAS measurements were performed using a Fourier-transform infrared spectrometer (Bruker IFS66v/S) with a mercury-cadmium-telluride detector. The incident beam was passed through a KRS-5 polarizer to remove the unwanted $s$-polarized component. All spectra were collected at a $4 \mathrm{~cm}^{-1}$ resolution over 200 scans. IRAS spectra were recorded at a sample temperature of $88 \mathrm{~K}$.

X-ray photoelectron spectroscopy. XPS measurements were performed at $300 \mathrm{~K}$ using $\mathrm{Mg} \mathrm{Ka}(1253.6 \mathrm{eV})$ radiation, along with a hemispherical energy analyser (Omicron EA125HR) and a seven-channel detector. XPS spectra were collected at an electron take-off angle of $40^{\circ}$ with a pass energy of $20 \mathrm{eV}$.

First-principles calculations. First-principles calculations for $\mathrm{Pt}_{n} / \mathrm{Al}_{2} \mathrm{O}_{3}$ were performed using the projector-augmented wave method based on DFT implemented in the Vienna $a b$ initio simulation package ${ }^{50}$. The generalized gradient approximation of the Perdew-Burke-Ernzerhof (PBE) functional was applied to the exchange-correlation energy ${ }^{51}$. The cut-off energy for the plane waves was set to $500 \mathrm{eV}$. The integral over the Brillouin zone was approximated by summation on a $3 \times 3 \times 1$ Monkhorst-Pack $k$-point mesh, and Gaussian smearing with a width of $0.2 \mathrm{eV}$ was applied. Optimization of the crystal structures was performed until the atomic forces were $<0.01 \mathrm{eV} \AA^{-1}$. The $\gamma-\mathrm{Al}_{2} \mathrm{O}_{3}(001)$ surface was modelled as a slab of a $\mathrm{p}(1 \times 1)$ cell. The crystal structure reported by Digne et al. was used for the bulk of $\gamma-\mathrm{Al}_{2} \mathrm{O}_{3}{ }^{52}$. The vacuum layer between slabs was set to $15 \AA$ (excluding the Pt cluster).

First-principles calculations on freestanding Pt particles were carried out using linear combinations of pseudo-atomic orbitals with the double zeta plus polarization quality as a basis set and norm-conserving pseudopotentials as effective core potential ${ }^{53}$. The computational parameters were the same as those used in our previous study ${ }^{53}$. Each NP was located in vacuum, and its structure was optimized to achieve maximum atomic forces of $<0.05 \mathrm{eV} \AA^{-1}$. The exchange-correlation interactions among electrons were described using the revised PBE functional proposed by Hammer et al. ${ }^{54}$.

\section{Data availability}

The source data underlying Figs. 1b-f; 2a; 3a, b, d, f, g; 4d; and 5b, c and Supplementary Figs. 2; 3a-c; 4a-h; 5e-h; 6g-i; 9b; 10; 11a-c; 12b, c; 14a-d; 15a, c, d; and 16a, e are provided as a Source Data file. Extra data are available from the corresponding author upon reasonable request.

Received: 28 November 2019; Accepted: 27 March 2020;

Published online: 20 April 2020

\section{References}

1. Zhang, J., Sasaki, K., Sutter, E. \& Adzic, R. R. Stabilization of platinum oxygen-reduction electrocatalysts using gold clusters. Science 315, 220-222 (2007).
2. Yamamoto, K. et al. Size-specific catalytic activity of platinum clusters enhances oxygen reduction reactions. Nat. Chem. 1, 397 (2009).

3. Crampton, A. S. et al. Structure sensitivity in the nonscalable regime explored via catalysed ethylene hydrogenation on supported platinum nanoclusters. Nat. Commun. 7, 10389 (2016)

4. Bratlie, K. M., Lee, H., Komvopoulos, K., Yang, P. \& Somorjai, G. A. Platinum nanoparticle shape effects on benzene hydrogenation selectivity. Nano Lett. 7 , 3097-3101 (2007)

5. Beniya, A. \& Higashi, S. Towards dense single-atom catalysts for future automotive applications. Nat. Catal. 2, 590-602 (2019).

6. Yoon, B. et al. Charging effects on bonding and catalyzed oxidation of $\mathrm{CO}$ on $\mathrm{Au}_{8}$ clusters on MgO. Science 307, 403-407 (2005).

7. Kaden, W. E., Wu, T. P., Kunkel, W. A. \& Anderson, S. L. Electronic structure controls reactivity of size-selected Pd clusters adsorbed on $\mathrm{TiO}_{2}$ surfaces. Science 326, 826-829 (2009).

8. Tyo, E. C. \& Vajda, S. Catalysis by clusters with precise numbers of atoms. Nat. Nanotechnol. 10, 577-588 (2015).

9. Ahmadi, M., Mistry, H. \& Roldan Cuenya, B. Tailoring the catalytic properties of metal nanoparticles via support interactions. J. Phys. Chem. Lett. 7, 3519-3533 (2016).

10. Heiz, U., Sanchez, A., Abbet, S. \& Schneider, W. D. Catalytic oxidation of carbon monoxide on monodispersed platinum clusters: each atom counts. $J$. Am. Chem. Soc. 121, 3214-3217 (1999).

11. Watanabe, Y., Wu, X., Hirata, H. \& Isomura, N. Size-dependent catalytic activity and geometries of size-selected Pt clusters on $\mathrm{TiO}_{2}(110)$ surfaces. Catal. Sci. Technol. 1, 1490-1495 (2011).

12. Cargnello, M. et al. Control of metal nanocrystal size reveals metal-support interface role for ceria catalysts. Science 341, 771-773 (2013).

13. Allian, A. D. et al. Chemisorption of $\mathrm{CO}$ and mechanism of $\mathrm{CO}$ oxidation on supported platinum nanoclusters. J. Am. Chem. Soc. 133, 4498-4517 (2011).

14. Kale, M. J. \& Christopher, P. Utilizing quantitative in situ FTIR spectroscopy to identify well-coordinated $\mathrm{Pt}$ atoms as the active site for $\mathrm{CO}$ oxidation on $\mathrm{Al}_{2} \mathrm{O}_{3}$-supported Pt catalysts. ACS Catal. 6, 5599-5609 (2016).

15. Moses-DeBusk, M. et al. CO oxidation on supported single Pt atoms: experimental and ab initio density functional studies of $\mathrm{CO}$ interaction with $\mathrm{Pt}$ atom on $\theta-\mathrm{Al}_{2} \mathrm{O}_{3}(010)$ surface. J. Am. Chem. Soc. 135, 12634-12645 (2013).

16. Therrien, A. J. et al. An atomic-scale view of single-site Pt catalysis for lowtemperature CO oxidation. Nat. Catal. 1, 192-198 (2018).

17. Ding, K. et al. Identification of active sites in $\mathrm{CO}$ oxidation and water-gas shift over supported Pt catalysts. Science 350, 189-192 (2015).

18. Hadjiivanov, K. I. \& Vayssilov, G. N. Characterization of oxide surfaces and zeolites by carbon monoxide as an IR probe molecule. Adv. Catal. 47, 307-511 (2002).

19. Aleksandrov, H. A., Neyman, K. M., Hadjiivanov, K. I. \& Vayssilov, G. N. Can the state of platinum species be unambiguously determined by the stretching frequency of an adsorbed CO probe molecule? Phys. Chem. Chem. Phys. 18, 22108-22121 (2016).

20. Watanabe, Y. \& Isomura, N. A new experimental setup for high-pressure catalytic activity measurements on surface deposited mass-selected Pt clusters. J. Vac. Sci. Technol. A 27, 1153-1158 (2009).

21. Beniya, A., Hirata, H. \& Watanabe, Y. Significant transient mobility of platinum clusters via a hot precursor state on the alumina surface. J. Phys. Chem. Lett. 7, 4710-4715 (2016).

22. Kresse, G., Schmid, M., Napetschnig, E., Shishkin, M., Kohler, L. \& Varga, P. Structure of the ultrathin aluminum oxide film on $\mathrm{NiAl}(110)$. Science $\mathbf{3 0 8}$, $1440-1442$ (2005)

23. Jaeger, R. M. et al. Formation of a well-ordered aluminium oxide overlayer by oxidation of $\mathrm{NiAl}(110)$. Surf. Sci. 259, 235-252 (1991).

24. Kwak, J. H. et al. Coordinatively unsaturated $\mathrm{Al}^{3+}$ centers as binding sites for active catalyst phases of platinum on $\gamma-\mathrm{Al}_{2} \mathrm{O}_{3}$. Science 325, 1670-1673 (2009).

25. Mei, D. et al. Unique role of anchoring penta-coordinated $\mathrm{Al}^{3+}$ sites in the sintering of $\gamma-\mathrm{Al}_{2} \mathrm{O}_{3}$-supported Pt catalysts. J. Phys. Chem. Lett. 1, 2688-2691 (2010).

26. Isomura, N., Wu, X. \& Watanabe, Y. Atomic-resolution imaging of size-selected platinum clusters on $\mathrm{TiO}_{2}(110)$ surfaces. J. Chem. Phys. 131, 164707 (2009).

27. Yoshinobu, J. \& Kawai, M. Thermal excitation of oxygen species as a trigger for the CO oxidation on Pt(111). J. Chem. Phys. 103, 3220-3229 (1995).

28. Palmer, R. E., Pratontep, S. \& Boyen, H. G. Nanostructured surfaces from sizeselected clusters. Nat. Mater. 2, 443-448 (2003).

29. Happel, M. et al. Adsorption sites, metal-support interactions, and oxygen spillover identified by vibrational spectroscopy of adsorbed CO: a model study on $\mathrm{Pt} /$ ceria catalysts. J. Catal. 289, 118-126 (2012).

30. Ke, J. et al. Strong local coordination structure effects on subnanometer $\mathrm{PtO}_{x}$ clusters over $\mathrm{CeO}_{2}$ nanowires probed by low-temperature $\mathrm{CO}$ oxidation. ACS Catal. 5, 5164-5173 (2015).

31. Jaeger, R. M., Libuda, J., Bäumer, M., Homann, K., Kuhlenbeck, H. \& Freund, H. J. Vibrational structure of excited states of molecules on oxide surfaces. $J$. Electron. Spectrosc. 64-65, 217-225 (1993). 
32. Liu, S. et al. Stabilizing single-atom and small-domain platinum via combining organometallic chemisorption and atomic layer deposition. Organometallics 36, 818-828 (2017).

33. Calle-Vallejo, F., Loffreda, D., Koper, M. T. M. \& Sautet, P. Introducing structural sensitivity into adsorption-energy scaling relations by means of coordination numbers. Nat. Chem. 7, 403-410 (2015).

34. Vila, F., Rehr, J. J., Kas, J., Nuzzo, R. G. \& Frenkel, A. I. Dynamic structure in supported Pt nanoclusters: real-time density functional theory and $\mathrm{x}$-ray spectroscopy simulations. Phys. Rev. B 78, 121404 (2008).

35. Shustorovich, E. Chemisorption phenomena: analytic modeling based on perturbation theory and bond-order conservation. Surf. Sci. Rep. 6, 1-63 (1986).

36. Larsen, J. H., Ranney, J. T., Starr, D. E., Musgrove, J. E. \& Campbell, C. T. Adsorption energetics of Ag on MgO(100). Phys. Rev. B 63, 195410 (2001)

37. Campbell, C. T., Parker, S. C. \& Starr, D. E. The effect of size-dependent nanoparticle energetics on catalyst sintering. Science 298, 811-814 (2002).

38. Parker, S. C. \& Campbell, C. T. Kinetic model for sintering of supported metal particles with improved size-dependent energetics and applications to $\mathrm{Au}$ on $\mathrm{TiO}_{2}$ (110). Phys. Rev. B 75, 035430 (2007).

39. Rieboldt, F. et al. Nucleation and growth of Pt nanoparticles on reduced and oxidized rutile $\mathrm{TiO}_{2}$ (110). J. Chem. Phys. 141, 214702 (2014).

40. Häkkinen, H., Abbet, S., Sanchez, A., Heiz, U. \& Landman, U. Structural, electronic, and impurity-doping effects in nanoscale chemistry: supported gold nanoclusters. Angew. Chem. Int. Ed. 42, 1297-1300 (2003).

41. Wang, Y.-G., Mei, D., Glezakou, V.-A., Li, J. \& Rousseau, R. Dynamic formation of single-atom catalytic active sites on ceria-supported gold nanoparticles. Nat. Commun. 6, 6511 (2015).

42. Pérez-Ramírez, J. \& López, N. Strategies to break linear scaling relationships. Nat. Catal. 2, 971-976 (2019).

43. Khorshidi, A., Violet, J., Hashemi, J. \& Peterson, A. A. How strain can break the scaling relations of catalysis. Nat. Catal. 1, 263-268 (2018).

44. Liu, J.-C. et al. Heterogeneous $\mathrm{Fe}_{3}$ single-cluster catalyst for ammonia synthesis via an associative mechanism. Nat. Commun. 9, 1610 (2018).

45. Xing, D.-H., Xu, C.-Q., Wang, Y.-G. \& Li, J. Heterogeneous single-cluster catalysts for selective semihydrogenation of acetylene with graphdiynesupported triatomic clusters. J. Phys. Chem. C 123, 10494-10500 (2019).

46. Frank, M. et al. Phonons of clean and metal-modified oxide films: an infrared and HREELS study. Surf. Sci. 492, 270-284 (2001).

47. Pang, C. L., Lindsay, R. \& Thornton, G. Structure of clean and adsorbatecovered single-crystal rutile $\mathrm{TiO}_{2}$ surfaces. Chem. Rev. 113, 3887-3948 (2013).

48. Beniya, A., Hirata, H. \& Watanabe, Y. Uniform deposition of size-selected clusters using Lissajous scanning. J. Vac. Sci. Technol. A 34, 031601 (2016).

49. Kaden, W. E., Kunkel, W. A., Kane, M. D., Roberts, F. S. \& Anderson, S. L. Size-dependent oxygen activation efficiency over $\mathrm{Pd}_{n} / \mathrm{TiO}_{2}(110)$ for the CO oxidation reaction. J. Am. Chem. Soc. 132, 13097-13099 (2010).

50. Kresse, G. \& Furthmüller, J. Efficient iterative schemes for ab initio total-energy calculations using a plane-wave basis set. Phys. Rev. B 54, 11169-11186 (1996).

51. Perdew, J. P., Burke, K. \& Ernzerhof, M. Generalized gradient approximation made simple. Phys. Rev. Lett. 77, 3865-3868 (1996).

52. Digne, M., Sautet, P., Raybaud, P., Euzen, P. \& Toulhoat, H. Use of DFT to achieve a rational understanding of acid-basic properties of $\gamma$-alumina surfaces. J. Catal. 226, 54-68 (2004).
53. Jinnouchi, R., Toyoda, E., Hatanaka, T. \& Morimoto, Y. First principles calculations on site-dependent dissolution potentials of supported and unsupported Pt particles. J. Phys. Chem. C 114, 17557-17568 (2010).

54. Hammer, B., Hansen, L. B. \& Nørskov, J. K. Improved adsorption energetics within density-functional theory using revised Perdew-Burke-Ernzerhof functionals. Phys. Rev. B 59, 7413-7421 (1999).

\section{Acknowledgements}

The authors thank Dr N. Isomura (Toyota Central R\&D Labs, Inc.) for STM measurements.

\section{Author contributions}

A.B. conceived and designed the experiments and performed the TPR, IRAS, STM, and XPS measurements. H.H. and Y.W. designed the apparatus. N.O. performed the DFT calculations, and N.O and R.J discussed the results. S.H. conceived the prediction method for the CO oxidation activity of nanoclusters. A.B. and S.H. prepared the manuscript. All authors discussed the results and commented on the manuscript.

\section{Competing interests}

The authors declare no competing interests.

\section{Additional information}

Supplementary information is available for this paper at https://doi.org/10.1038/s41467 020-15850-4.

Correspondence and requests for materials should be addressed to A.B. or S.H.

Peer review information Nature Communications thanks the anonymous reviewer(s) for their contribution to the peer review of this work. Peer reviewer reports are available

Reprints and permission information is available at http://www.nature.com/reprints

Publisher's note Springer Nature remains neutral with regard to jurisdictional claims in published maps and institutional affiliations.

Open Access This article is licensed under a Creative Commons Attribution 4.0 International License, which permits use, sharing, adaptation, distribution and reproduction in any medium or format, as long as you give appropriate credit to the original author(s) and the source, provide a link to the Creative Commons license, and indicate if changes were made. The images or other third party material in this article are included in the article's Creative Commons license, unless indicated otherwise in a credit line to the material. If material is not included in the article's Creative Commons license and your intended use is not permitted by statutory regulation or exceeds the permitted use, you will need to obtain permission directly from the copyright holder. To view a copy of this license, visit http://creativecommons.org/ licenses/by/4.0/.

(C) The Author(s) 2020 